\title{
Psychotherapy with two late adulthood children of the colonies
}

\author{
Zelda Gillian Knight \\ Department of Psychology, University of Johannesburg, Johannesburg, South Africa
}

\begin{abstract}
There are a small group of mature adults in their $50 \mathrm{~s}$ and $60 \mathrm{~s}$, members of the so-called third age that arrive at the door for psychotherapy. As clients, they want to explore an overwhelming sense of being dis-located in space and time, and at odds with where they find themselves living. They have a deep and profound sense of not belonging and of being rootless. These older, white, adults are the baby-boomers of post World War II, and I refer to them as the adult children of the colonies because they are of European descent but born in the colonies of Africa. This paper describes the

Correspondence: Zelda Gillian Knight, Department of Psychology, Faculty of Humanities, Auckland Park Campus, University of Johannesburg, Johannesburg, South Africa.

Tel: +27-83-311-3229.

E-mail: zknight@uj.ac.za

Citation: Knight, Z.G. (2017). Psychotherapy with two late adulthood children of the colonies. Research in Psychotherapy: Psychopathology, Process and Outcome, 20(3), 210-219. doi: 10.4081/ripppo.2017.287

Acknowledgements: This work is based upon research supported by the National Research Foundation, South Africa. Any opinion, experiences of two clients, Robert and Caitlin, who find themselves feeling progressively psychically dis-located in South Africa and confronting not only their limited future in terms of impending death, but confronting existential givens of life that prevent them at this late stage of life from returning home to their ancestral lands. They present a unique group of older adult clients, and like fish out of water, they have no sense of belonging to Africa, and as a result, they experience a range of emotions such as despair and depression with a concomitant sense of fragmented identities. Discussion of the cases ensues and includes the concept of intergenerational transmission of trauma, fragmented identities, and belonging as linked to ancestral lands.
\end{abstract} findings and conclusions or recommendations expressed in this material are those of the author(s) and therefore the NRF do not accept any liability in regard thereto.

Conflict of interest: The author declares no potential conflict of interest.

Information about the author: The author is a $\mathrm{PhD}$ graduate of Rhodes University, South Africa, and an experienced practising psychotherapist as well as a Professor of Psychology at the University of Johannesburg. She has been lecturing for many years, and has a substantial publication record with works published in international journals and academic books. She is an NRF Rated Scientist in her country, which means that she is recognised by peers as an expert within the field of psychodynamic psychotherapy. She has presented numerous papers at international conferences worldwide, including being a keynote speaker on several occasions. She is currently the Vice President of the World Council for Psychotherapy (African Chapter), and on the Editorial Board of several academic journals in psychology and psychotherapy. She is involved in psychodynamic psychotherapy training of Master's students in Clinical and Counselling Psychology at the University, and has extensive experience as a research supervisor. She is interested in working with concepts and processes in psychodynamic psychotherapy, and has recently edited two books on psychoanalysis and psychotherapy.

Received for publication: 11 August 2017.

Revision received: 17 October 2017.

Accepted for publication: 18 October 2017.

This work is licensed under a Creative Commons Attribution NonCommercial 4.0 License (CC BY-NC 4.0).

(C) Copyright Z.G. Knight et al., 2017

Licensee PAGEPress, Italy

Research in Psychotherapy:

Psychopathology, Process and Outcome 2017; 20:210-219

doi:10.4081/ripppo.2017.287
Key words: Late adulthood; Intergenerational trauma; Psychotherapy; Identity.

\section{Introduction}

Maturity in adulthood is not automatic but a developmental achievement marked by several life-transitions all of which call for adults to use previously obtained ego strengths and skills to confront the new world of adulthood and ageing. Erikson (1950, 1968, 1982; Erikson, et al., 1986) was the first theorist to understand that psychosocial development spanned a full and entire life cycle and included the development of positive ego strengths or virtues that emerged out of the successful integration of opposing psychological tendencies which could result in abilities to manage current life challenges. Life as an adult in the years of later adulthood, after the normative developmental tasks of child-bearing and child-rearing and the parenting of both children and ageing parents, has a different set of challenges and promises.

Some of the challenges are finding a new sense of self in the wake of social and family structures that essentially fall away that in the past gave meaning to life, such as the world of work or/and mentoring the next generation. For some adults in their $50 \mathrm{~s}$ and $60 \mathrm{~s}$, this is a period that is a fundamentally a time for reflection and introspection as there is now more time for the self. Jung (1971) wrote of the second half of life as an important time in the psycho- 
logical development of adults. He described this period of life as engaging with the process of individuation and the find of the Self which included the integration of aspects of the self previously denied. Some of these mature working adults experience a later-life crisis (Robinson \& Stell, 2015) as opposed to the more well-known phenomenon of a mid-life crisis (Lachman, 2004; O'Connor \& Wolfe, 1987). It becomes a developmental turning point which can involve negative and positive outcomes. When it is a positive outcome, it is a re-invigorating process that results in a better lifestyle with decisions for the future based on a positive outlook (Robinson \& Stell, 2015). Erikson (1950, 1968, 1982; Erikson, et al., 1986) used the term crisis not as a developmental calamity but as an opportunity for life change.

It seems, however, that the process of a developmental crisis often contains periods of heightened vulnerability and instability that could last months to years (King, 2001; Robinson \& Stell, 2015). Not everyone has a crisis in their later-years. There are, however, a small group of these mature, working, adults in their $50 \mathrm{~s}, 60 \mathrm{~s}$ and early $70 \mathrm{~s}$, members of the so-called third age (Weiss \& Bass, 2002) that arrive at the door for psychotherapy. They are mostly successful in terms of achieving wealth, status and social recognition. As members of the third age they don't always need to work (Weiss \& Bass, 2002) but choose to work as it gives them a sense of meaning and purpose. They have sufficient health to live independently as well as sufficient income to engage in leisure pursuits (Weiss $\&$ Bass, 2002). These adults are generally in a state of freedom and fulfilment (Laslett, 1989) but may have one or two concerns or problems in living that they need to work on in therapy. They appear to use therapy as a process of self-discovery and personal growth. This group are from various ethnicities and racial-cultural backgrounds. The therapy process is reminiscent of the Jungian process of individuation in the face of existential concerns more typical at this stage of development. Some of these older clients who come to therapy, however, find themselves exploring an overwhelming sense of being dis-located in space and time, and at odds with where they find themselves living. They have a deep and profound sense of not belonging and of being rootless.

It is this group of older adult clients, mostly white members of the third age that this paper seeks to describe and explore in terms of moments in therapy.

These older white adults are the adult baby-boomers of post World War II. They are, what I refer to as, the adult children of the colonies because they are of European descent, born and currently living in what were the European and British colonies of Africa. In post-World War II, many of their parents left war-torn Europe and Britain to seek life elsewhere, and settled in the Dutch, English, German, and French colonies of Africa (such as the Algeria, Congo (now Democratic Republic of the Congo), the Federation of Rhodesia and Nyasaland (now Malawi, Zambia and
Zimbabwe), German South West Africa (now Namibia) and South Africa.

While this mass white migration after World War II to the colonies initiated numerous political clashes and social upheavals in the colonised lands, these adult children of the colonies grew up ostensibly separate from their ancestral lands (of Britain, for example) and their own culture and kin associated with those lands. With the historical turn and transformation of politics and governments in these previous colonies, some of these mature, older white adult children of the colonies find themselves having emotional and psychological concerns that are unique to their social situatedness or the existential throwness (Heidegger, 1962) of being born and raised in Africa, but not of Africa nor African. They find themselves living and working and raising a family in a de-colonised country (in this case, South Africa), which is for them increasingly and essentially alien and unknown because they report that in the changing political milieu of South Africa their white culture has become demonised and politically less valued where it once was one of significance in terms of political power and influence.

\section{What this paper is about}

This paper describes and examines the experiences of two clients, Robert and Caitlin, who find themselves feeling progressively dis-located, disenfranchised, and confronting not only their limited and limiting future in terms of impending death, but confronting existential givens of life that prevent them at this late stage of life from returning home to their ancestral lands. In a sense, these older, white adults are Scatterlings of Africa) members of a white ethnicity spread across the African continental that has become unfamiliar and unrecognised. Note that Scatterlings of Africa is a track featured on the studio album Scatterlings by Juluka, a South African band led by Johnny Clegg and Sipho Mchunu. It was first released in 1982.

They present a unique group of older, adult clients because, as indicated, their clinical presenting problems are a profound sense of being psychically dis-located from their ancestral lands, and of feeling rootless and unhappy. They often travel to Europe or Britain on business or holiday, and on their return to Africa they describe feeling unsettled and wishing to be back in Europe or Britain. They are fairly wealthy clients who can afford to travel overseas even in the light of the weak South African currency.

Below are two descriptions of a therapy process that provides a glimpse into two clients' and their experiences of feeling they have no belonging and thrown into a situation where they feel that the country of their birth and citizenship is alien and unfamiliar. A discussion of the two cases follows.

This paper is not a political or social commentary on the colonialization of Africa. Instead, these therapy cases are an example of a growing number of European clients that come to therapy and have concerns and feelings of 
being dis-located in time and space while living in their country of birth. The development of these kinds of lived experiences in the therapy room are unusual, and with any new lived experience, need to be documented and understood.

The two clients documented in this article present with the clinical diagnosis of major depression, coupled with a sense of rootlessness due mostly to their existential sense of being as not belonging. The therapeutic modality is psychodynamic and descriptions of the therapy are description of moments in therapy as opposed to the whole therapeutic process.

\section{Moments in therapy}

As an introductory note it must be stated that all identifying data of clients have been disguised. In some instances, case material has been made up from various similar cases so as to make it impossible to further identify the clients.

\section{A stranger in a strange land: The case of Robert}

Robert had been a professional consultant in the corporate sector most of his working adult life, travelling extensively across the world to various academic conferences and workshops. At forced retirement age of 60 years old he started a new private practice as a consultant. This new work made him feel invigorated and relevant in terms of being able to continue to contribute to society. He was obsessed with how he looked, and did not want to appear old because he felt his younger clients would think of him as an old fuddy duddy so he had cosmetic surgery - a face lift - in the previous year. He dressed well, always came to therapy in a suit and tie, and wore expensive shoes and drove a luxury car. He was a successful man if the social measurement of success is wealth. From appearances he could have been mistaken for a man of 52 years. When he came to see me for therapy he was 61 years old, and he reported that he found himself sinking into a deep depression despite having a successful business and a good family life.

During therapy he spoke about and identified the trigger event of his depression. He described this event. It had been during a recent return trip from the north of England where he had joined other friends for a short summer holiday. He reported that during this trip he had attended various professional workshops aimed at furthering his own skills. He had enjoyed the time overseas and felt relaxed and at home, as if he had returned home. He emphasised that it was a return to my ancestral home. He explained that there was one particular rural English village where he felt 'alive in, and could easily settle in and live and make a place for myself and my wife. He shared an experience of finding himself outside one day on the streets of this small English village and he could hear the sound of the music of Handel and Mozart being played by a few musicians. He remembered how animated, excited and invigorated he felt in that moment, with an overwhelming sense of belonging. He reported a deep connection to the ancestral lands, a returning home.

He became sad and tearful at this point in the therapy. As he spoke further he reported that he had no real roots here (in South Africa) no roots to the land he lived in despite being born here. He had no attachment to anything of this place. He had been overseas several times but this particular return trip had catapulted him into feeling down and unsettled as if a switch had gone off inside. In exploring these depressed feelings in therapy he said that the trip to England had made him realise that Africa was not home. He instead felt rooted and at home in England. Being in South Africa made him feel rootless, dis-located and away from his ancestral lands.

In further elaboration of his experiences he spoke of his ageing parents, both in their 90s, and explained that they had been born in England and had decided to move to South Africa soon after World War II. He reported that his parents had been extremely upset and traumatised by the war having lived in London at the time of the bombings of London. They had actually met in an underground bomb shelter of London. They moved because they both wanted to find a better place to live and safely raise their children. South Africa was a well-established colony and they decided to leave England to find a home in the colony. In therapy he shared mostly happy memories of growing up as a child in the colonies and listening to both the horror and the inspiring stories of his parents' experiences of the war. He happily referred to himself as a child of the colonies when he later travelled overseas as an adult, signifying to others that he was different because of his personal and collective history of being born in a colony.

During one session he reported another experience that he had when he landed back in South Africa after this recent visit to England. He said he was standing in a queue at the passport control at the international airport in Cape Town when he heard the sound of African music being played over the sound system. It felt alien to him and it disturbed and jarred him as if something was being pushed uninvited into his psyche. While he had heard African music all his life, and while he did not feel any resonance with it, this time at the airport it felt intrusive and invasive. In exploring this experience further, he realised that it was not so much the African music that he did not like but he suddenly felt the alien, the intruder, the invader and uninvited settler in Africa, and that while the African music belonged here he did not belong here. He felt an overwhelming sense of being a stranger in a strange land, a visitor to an unknown place.

We explored these feelings of being a stranger in a strange land and related it to his own internal life and processes as well as the wider, social world, the feelings were always about a sense of not belonging in Africa, of 
being rootless in Africa. He also spoke of feeling trapped in Africa and split at the deepest part of his being. He became more depressed as he explained that he felt his chance of leaving the country was not realistic because it would be madness to start again at his age. He explained that time was against him but he had a longing to re-connect to his ancestral lands.

As we worked with his feelings of despair and sadness, it also emerged that he had mathematically worked out that he had about 7000 days left of productive working life. He had worked this number by using 15 years as a maximum period of life for himself. This working out the number of days left was a tense moment of confrontation with his own sense of finiteness: of his limited life and limited future. As therapy progressed over the next few moments he began to look back on his life and examine some of the life choices he had made. When it came to discussing in therapy his decision not to leave the country all those years ago when he could have and was much younger, he expressed regret and despair and later began to weep.

Robert continued in therapy for the next several months. The phenomenological themes of not belonging and a need to re-connect to his ancestral lands continued to dominate the process. He was medicated for the depression, and while therapy continued for several months, it would be false to claim that he never fully recovered from the depression. He did, however, despite the depression, manage to continue to work, but he claimed that he would always feel dis-placed in Africa with no real sense of belonging.

\section{A fish out of water: The case of Caitlin}

Caitlin was a 50-year-old professional woman when she came to therapy. She dedicated her life to being a teacher. She had been born in a small rural town in South Africa and spent most of her adult life living in small towns. She came to therapy because she felt depressed and unable to find any joy in her work. While she went to work she felt that she was just going through the motions and had no energy. She was also sleeping more.

In therapy she explained that she had recently returned with her husband from their annual summer holiday to England. They had been doing this trip for many years and each time she came back home to South Africa she felt oddly unsettled and unable to feel a sense of belonging. She said it took her a long time to get back into the daily routine and focus on work. On this last trip she returned feeling unable to settle into any routine and while she went to work, everything at work seemed difficult.

We explored her feelings of being unsettled in the wake of her recent return. While she also spoke about the mass corruption at government level, the unprecedented levels of crime and violence, therapy was not about a ranting and raving against a failed state, but more about her a sense of not belonging in Africa. She shared that being older was a time of thinking about things, and of looking back and exploring the past. She reported that she felt re- gret for lost opportunities. On this recent trip to England she reported that she felt alive, vibrant, excited, and safe from crime and violence. She explained that when she came back to South Africa she was struck by feeling tense and overly vigilant about her security. She was also more conscious of the increasingly strong emphasis on racial politics. We explored these feelings and while she considered herself anti-racist, she had a growing sense of being demonised because she was white. She said she felt sadly unwanted as a white person and often marginalised.

Caitlin reported that she had once been an active antiapartheid activist during her student days, and a member of the banned political party seeking to bring about change in South Africa. But now, in therapy, she felt a sense of dis-location and at odds with the world in which she now lived. She was struggling to find my place in the new, post-apartheid South Africa amidst the progressively anti-white sentiment. This loss of place made her feel despairing and alone.

Caitlin explained that she was born in South Africa to parents of combined Dutch and English ancestry and her mother tongue was English. Her schooling was modelled on the British system of $\mathrm{O}$ and $\mathrm{A}$ levels, and she, similar to Robert's parental history, had parents who had escaped World War II in 1944. Her parents also left for the colonies (South Africa) with hopes for a better future. She reported that she felt a loyalty to her parents' dreams for a better life in the colonies, and she said that maybe that was why she never left the country.

During the many trips and holidays overseas, Caitlin had begun to increasingly feel a sense of rootlessness and despair that she interpreted as an existential despair about being in a country that does not feel like my own. In further elaboration of this despair she explained that she felt that she had a sense of not belonging in South Africa. We explored this feeling of rootlessness and of not belonging, and she further explained that living in Africa and South Africa was like living like a fish out of water: everything was out of place and until she was back on her ancestral lands, she felt she was always gasping for breath. She shared that while Africa was the place of her birth, she did not feel she fitted in anywhere except back in England, her ancestral home. In the session, she said that she would give anything to go back there as nothing European is preserved in South Africa. She said she could find a way to live in England, to start again, and make a living. But she also knew it was unrealistic to leave South Africa at her age as she was not young anymore.

In the moments in therapy, she felt her sense of self was broken by living in a place that had anti-white sentiments. She felt split inside because she related to the European world of England, and that living in South Africa she felt dis-jointed and fragmented within. England, she reported, was her ancestral land and where she felt she belonged. She said, It's not that England is white and I can't adjust to black South Africa... England is more 
multi-cultural and racially tolerant than South Africa.. England is neither white nor black but is the place of my ancestors and I feel a connection to the land and to my ancestors ... I am rootless in South Africa.

In further exploring this experience of dis-location and not belonging, she spoke of being from a lost, white tribe that had been scattered across the world' after World War II so that there were "no links between us anymore. She spoke of her lost, white tribe as Scatterlings of Europe (a play on the music album she knew about and what was referred to earlier) and that the tribe would always be scattered, lost, with no real place or land to settle on or to find roots. This discussion linked to a topic about how she felt she had no real meaning in her life because she felt she did not belong where she now lived. We explored her personal sense of being lost, scattered and rootless.

She also spoke of her time as limited because she was getting older and this led to her working in therapy with her own finality in the face of her limited future. She felt regret for things not done in the past, such as not leaving South Africa. Along with this regret, she felt a despair regarding her ageing process and that she had less time. She linked this limited time back again to this sense of not belonging and of being dis-located and wishing, in fantasy, to go back to England.

Caitlin remained despairing throughout the therapy. While she was medicated for her depression, her sense of sense of struggling to fit in, and find meaning and belonging, remained. My last session with her six months later was that she had decided to retire from work and move to the coast.

\section{Discussion}

There is very little written about the experiences of white adults in late adulthood and children of the colonies in Africa. There is even less understood about their experiences of feeling dis-located when living in Africa. This paper has described the therapy process of the two clients and it begins to give some understanding of the experiences of the adult children of the colonies. These two cases are examples of many other clients in the past few years who have expressed similar feelings and who have been in therapy to work through their sense of feeling dis-located when living in South Africa, especially after a return trip to their ancestral lands. The discussion here is tentative and can only be based the two cases. Any conclusion is specific to the case material. In this way, the discussion serves for a generation of ideas and discussion. While the therapy cases can be interpreted in different ways, and perhaps they can be almost dismissed as the ramblings of two maladjusted and unhappy white older adults who find themselves confronting issues of their whiteness in Africa, something that has been a topic of the psychoanalytic therapeutic community in recent years (Straker, 2004; Suchet, 2004; Swartz, 2007), there is a need to open up the therapeutic dialogue on this group of mature and ageing clients in order to fully appreciate their phenomenological world and the unique context in which they live.

\section{Belonging as linked to ancestral lands}

This particular white dispersed generation of children of the colonies in their 50s and 60s, such as Robert and Caitlin, are the social-political bi-product of the chaos of World War II and the resultant European voluntary migration to the African colonies. They are a group of mature, white adult baby-boomer clients, born on African soil but descendants of European ancestry. They are a unique group of clients because they are born into a European culture and yet simultaneously raised in Africa with African influences. For example, Robert said he had always known African music. The implication is that for Robert and Caitlin this experience of whiteness in Africa results in a split between their senses of self as rooted to their ancestral lands and the culture of their parents, and their need to also forge identities for themselves while being born in Africa. It can be suggested that their experience is one of not belonging in Africa and belonging only as linked to ancestral lands. In other words, for Robert and Caitlin they experience themselves as dis-connected from their European ancestry and ancestral lands while being life-long citizens of Africa. Their sense of identity and belonging is linked to their ancestral lands rather than to Africa. The implication is that this sense of belonging only emerges when they return to their ancestral lands implying that they live in Africa with a sense of identity that feels rootless and disjointed.

\section{Fragmented identity}

Identity is formed through personal experiences within a certain social-cultural setting and is not separate from that social setting. Erikson $(1950,1982)$ used the term identity to refer to a specific part of the self that is arranged, constructed, and eventually told (McAdams, 1995, p. 385) and that provides the quality of unity and purpose of the self (McAdams, 1995, p. 385). Identity thus refers to the parts of the self that are integrated and psychically put together or structured so that individuals have a sense of knowing who they are; it is that aspect of the self that is integrated (Erikson, 1950). Erikson (1950, 1982) made the point that psychological development as linked to identity formation is always intertwined with a cultural and social context that gives meaning to a sense of self, and vice versa, such that social institutions emerge to support psychological development. Erikson's theory of identity has been best developed by James Marcia (Kroger \& Marcia, 2011) and more recently by others (Brubaker \& Cooper, 2000; Jackson, 2010; Martinussen \& Kroger, 2013; Schwartz, 2002, 2011; Stevens, 2008). The extended contemporary theory of identity is less abstract than Erikson's version and suggests that the nature of identity formation is best understood as that which is 
based on manifest behaviours. Such behaviours are the result of life choices throughout the life cycle, such as the choice of an occupation, or the choice to believe in an ideology (Kroger \& Marcia, 2011). Identity is expressed in exploring and a commitment to various ways of being and behaving, whether in ideological or occupational realms (Kroger \& Marcia, 2011).

For some individuals, however, especially in later adulthood when life choices are reduced due to the ageing process and social changes in roles and responsibilities, their sense of self changes. It is suggested that in the case of Robert and Caitlin their sense of self is based on the on-going and dominant life experiences of feeling rootlessness which is linked to (a loss of) their ancestral land. As they live in a country that is not experienced as their own, while another country does, their sense of self is always divided. It becomes a fragmented identity. This point may have an implication for therapy with immigrants in that their identity may be drawn from experiences of the lands they have left and once were connected to. Extending this further, for Robert and Caitlin there is a marked disjuncture between the lived socio-cultural reality of their parents who consciously chose to leave their ancestral home lands but still found themselves raising their children according to their own developmentally inculcated norms rather than the norms and values of the African culture into which their children would be growing. Therein lies a fragmentation and breakdown between the reality of living in a colony but being raised as if still in the ancestral land. The implication for Robert and Caitlin is that they find themselves struggling to make sense of their European-ness in the context of African-ness, and in terms of identity, their behaviours, from which such identity is expressed (Kroger \& Marcia, 2011), becomes one of (a futile) attempt to find their place in a divided world.

Moreover, Robert and Caitlin's sense of not belonging except when visiting their ancestral lands speaks to the unusual phenomenon that belonging is linked to meaning. While they have no sense of belonging they had no real sense of existential meaning, and with a fragmented identity, the finding of meaning becomes difficult and perhaps equally fragmented. This lack of meaning in life that both Robert and Caitlin describe may account for their depression and sense of being dis-located in time and space. In addition, with no meaning, identity becomes one of groundlessness and the inability to anchor to something that could provide (the missing) meaning such as an ideology, a place, a group, an idea, a relationship, or a religion. To re-cover a sense of meaning Robert and Caitlin would have to establish a sense of belonging which is based on links to their ancestral lands where their psychological roots are.

\section{Existential concerns}

Existential concerns become heightened as one ages and death itself is less abstract. Mature adulthood or the second half of life (Jung, 1971) comes with a consciousness of not only physical and psychosocial changes but it also a critical period of life when many adults realize that their time is limited. This realization is a common trigger for a later life developmental crisis or later-life crisis (Robinson \& Stell, 2015). Underlying a developmental crisis or turning point in life is a core concern regarding the passing of time and the limiting of opportunities. Such a realization of one's limited time essentially concerns a confrontation with one's finiteness and the existential given of death, which is the ultimate boundary. Many older adults begin to, as a result of this awareness of mortality, create a legacy (Hunter \& Rowles, 2005; Kane, 1996; Kotre, 1984; Newton, et al., 2014) and begin to focus inward, or pay attention to aspects within themselves - an idea put forward initially by Neugarten (1964, 1968) of adulthood interiority - which involves an emphasis on inner reality and the discovery of meaning and direction from within rather than from outside. This introspection is a hallmark of growing older and it facilitates the confrontation of one's finiteness.

Together with this awareness of one's finiteness comes an awareness of other existential concerns-meaning, isolation and freedom/responsibility (Spinelli, 2015; Van Deurzen \& Arnold-Baker, 2005; Van Deurzen \& Adams, 2011; Yalom, 1980, 2001, 2006; Yalom \& Leszcz, 2005). For adults in their later years, an awareness of limited time and thus impending death is always the shadow that lies behind everything else. Since the pioneering work of Yalom (1980) existential concerns have continued to be a dominant theme with older adults in therapy (Becker, 2006; Spinelli, 2006, 2008, 2015). For Robert and Caitlin, their sense of their own limitations and finality was indicated by their repeated reference to their age and their sense of time as short. Time was against them. Time and age shaped their current inner conflict of rootlessness and the knowledge that their limited time does not allow for them to begin life again in England. Limited time for them is painfully confronted, and results in depression, despair and regret. With a closing off of the future horizon of future possibilities, their present experience is one of remorse for not having immigrated earlier in their life when they could have. They are both trapped by their age and the realization that it is too late for some things: this raw realization that some things are lost, unfinished and incomplete encompasses so much of their therapy process.

Viktor Frankl (1963) writes of an existential vacuum created in states of disidentification when there are no apparent clearly-defined demands and expectations from the environment, and individuals themselves are unsure of their role. The situation generates anxiety by requiring decisions that must come from the self and the inner world (Becker, 2006). Middle age and later adulthood, which follows on the construction and settling down of young adulthood, constitutes a kind of existential vacuum in which personal existential meaning must be found without the context of 
external demands or expectations (Becker, 2006) either because they are too heavy a burden to maintain or because they have ceased to exist, as in the case of the empty nest syndrome. In the case of Robert and Caitlin the sense of an existential vacuum is created more so by the disidentification to the place where they live rather than by an emphasis on the social roles that contribute to the creation of a sense of existential meaning. While the empty nest syndrome may also apply to them, they find no meaning because they feel at odds with the land, and the African world: they feel a stranger in a strange place, a member of a lost, white tribe, and as such, their sense of an existential vacuum, expressed as rootlessness and loss, is best understood as Scatterlings of Africa where there is no personal or collective identity to the foreign lands.

The implication is that growing older in a place and land not rooted to, as with Robert and Caitlin, gives rise to a sense of existential meaninglessness. Meaning, therefore, is linked to an identification with land but it is also heightened by ageing in that meaning changes with age, and identifications also change with age. The meaning of not belonging is not something that happened when Robert and Caitlin were young. As they grew older, as they travelled more, as they came back to South Africa after a recent trip, their meaning to living in South Africa became one of not belonging. Ageing becomes a time of finding new meanings in new circumstances, and when this does not happen, it can result in a developmental crisis that has negative outcomes. In a sense, Robert and Caitlin were having a developmental crisis with existential flavourings.

\section{The intergenerational transmission of trauma}

The psychoanalytic concept of intergenerational transmission of trauma (Garon, 2004; Muhlegg, 2016; Volkan, 1997) posits that psychological trauma experienced by the parental generation is transmitted to the next generation. The implication is that the children absorb the emotional effects of the trauma of the survivor parents: the trauma is re-visited upon the children. This concept appeared to emerge more fully after World War II. There is a plethora of literature on the subject of how Holocaust survivors have inadvertently negatively affected the lives of their children (Bergmann \& Jucovy, 1982; Kogan, 2002; Levine, 1982). The concept entails that the emotional constellation of the psychological effects of trauma that is unprocessed or unsymbolised (Muhlegg, 2016) by the survivor parents is psychically absorbed by their children. In this way, the children are the psychological reservoirs for their parental unprocessed traumas. Freud (1920) reminds us that which is unprocessed is relegated to the unconscious but it continues to have impact on the lives of individuals, and will seek to return to conscious, often as the symptom. As such, these children live their lives in the shadows of these parentally transmitted and internalised trauma.
Moreover, this intergenerational mechanism of transmission displaces the unfinished task of working through the trauma onto the next generation so that the children are supposed to undo the trauma and prevent it from ever happening again, as well as reverse the feelings of helplessness belonging to the family of the previous generation (Volkan, 1997). The implication is that the targeted children are expected to work through the unprocessed trauma of the survivor parents: to complete the unfinished work of the survivor parents.

In the case of Robert and Caitlin, they are the inheritors of their parental trauma of the same war that gave rise to the same Holocaust survivors. While much has been written about the Holocaust survivors, little has been documented about the children of the colonies who are the children of the parents of post World War II who chose to move to the colonies as a way of dealing with their trauma. They were not forced to move and thus they were not refugees. These children of the colonies, like Robert and Caitlin, carry within them the transmitted parental disavowed and painful parts. However, it is more complicated than this. In order to cope with the trauma of the war, their parents chose to up-rooted themselves from war-torn lands of Britain with a hope for a better future for themselves and their unborn children. This choice is significant because it meant that the parents were welcomed in the new lands by other settler Europeans, and as such, the new lands mimicked the motherland. The parents re-created white culture in African lands: they made the new land into replicas of the ancestral lands back home. For Robert and Caitlin, not only were their parental war trauma displaced, to some extent, by the human mass movements to Africa, but the trauma also coalescent into hope. The hope to start life again. The hope to start life in a new land. But this hope is perhaps a defence against the full realisation of the trauma. Hope and trauma, in this case, and one of the many unwritten and unspoken aspects of the legacy of white colonization is that it gave rise to a generation of Europeans living in Africa that feel at odds with the African world in which they find themselves living.

Robert and Caitlin were expected to live out and fulfil these parental hopes. They are loyal to the parental transmission of hope. Part of the distress is based on the idea that to leave South Africa is to betray the parental transmission of hope: to betray the hope would be to betray the parents. They simultaneously live with regret for not leaving. As they age, they live with a growing sense of it is too late to leave, which, together with existential concerns of ageing in the context of being dis-located, manifests in depression and despair.

\section{Despair versus Integrity}

It can be seen that Robert and Caitlin are depressed and despairing. They face ageing life with a sense of being dis-connected from the land and perhaps from self too. Erikson's (1950; Erikson et al., 1986) eight stage model 
of psychosocial development posits a particular dialectic as the dominant concern in old age: Integrity versus Despair (Bradley \& Marcia, 1998; Robinson \& Stell, 2015). These two opposing psychological tendencies of being and relating need to be integrated, in equal measures, for the ego strength or virtue of Wisdom in old age to emerge (Erikson, 1950, 1982; Erikson et al., 1986). Integrity manifests in the personal acceptance of the past, present and perceived future of one's own life (Erikson et al., 1986). Acceptance of the past necessitates not dwelling excessively on regrets, painful memories or secrets, and resolving any past conflicts with family or friends (Maslow, 1968; Torges, et al., 2008). Acceptance of the present comprises finding gratification with how life is rather than how it could be, and thus not struggling against the inevitability of one's current life circumstances (Viney \& Tych, 1985). Acceptance of the future involves finding contentment and peace with the idea of having to scale back some activities with age, with asking for help more (James \& Zarrett, 2006) and with the prospect of death and dying (Erikson et al., 1986).

At the opposite end of the dialectic, according to Erikson, Despair is characterised by rumination over past mistakes, and a desire to turn back time to an age when life still held meaning (Robinson \& Stell, 2015). Erikson $(1982,1986)$ asserted that despair brings with it a feeling that one is running out of time, that life is too limited or short and that there is only a finite amount of opportunity to find peace, order and meaning (Robinson \& Stell, 2015). It results in a fear of mortality and dying and an internal protest at the idea of being an old person (Ryff \& Heincke, 1983).

In the light of this Eriksonian developmental task of the integration of the two opposing poles of Despair and Integrity in terms of the past, the present and the future, for Robert and Caitlin their developmental task seems incomplete. On a superficial level, Robert does not want to appear as an old fuddy duddy so he has cosmetic surgery to disguise his ageing. He protests against the idea of being an old person. But this protest is perhaps a way to disguise the despair he feels. He is not at peace. Nor is Caitlin at peace. Being dis-located and with a fragmented identity, despair is an existential Despair that time is too short to go back to the ancestral lands. The opportunities to leave South Africa have passed because they are old to move and begin life again. Despair governs their lack of acceptance of the past and what could have been had they lived in England and not Africa. They dwell excessively on regrets. Despair rules over their present-time as they find themselves out of place.

\section{A brief note on the therapist's reflections}

The therapist voice and subjectivity is always important in modern therapies (Aron, 1997; Benjamin, 2005). A case analysis of these two clinical cases presented in this paper cannot be done without a perspective that in- cludes the therapist's subjectivity. What clients bring to therapy is often a co-creation of the two members of the dyad such that the co-mingling of the subjectivities results in analytic material that is partly the therapist's and partly the client's (Aron, 1997; Benjamin, 2005). This paper has focused less on the therapist and the transference-countertransference matrix in order to give emphasis to the voice of the clients. However, it is recognised that my whiteness may have had an impact on the whiteness of the clients (Swartz, 2007). Perhaps my own concerns about finding a place in Africa as a child of the colonies may have been unconsciously communicated to them. This issue of my whiteness was explored with them both, and it is recognised that my subjectivity must have played a part, to some extent, in the nature of the analytic material that emerged. To this end, Robert and Caitlin appeared to have positively responded my (whiteness) race, as well as other mirroring influences such as similar upbringing, culture, and educational background, and, as a result, felt freer to talk about their whiteness in terms of their sense of not belonging in Africa.

\section{Conclusions}

The trauma of the colonised has been recognised (for example, the work of Frantz Fanon in the 1950s) but the therapeutic experiences of adult white children of the colonies is mostly silent and unknown. This silence is perhaps because these clients are understand by the colonised as the oppressors and their story and experiences are less relevant. Psychoanalytic theory informs us that that psychic pain that is ignored, denied and repressed, not only a personal level but a generational and collective level, will remerge as the return of the repressed (Freud, 1920). Robert and Caitlin are representative of an increasing number of white adult clients in South Africa that are experiencing particular feelings associated directly with being children of the colonies. This paper set out to describe what is happening in the lifeworld of two clients. Therapy with this specific group of adult children of the colonies with these specific presenting clinical concerns has not been, to my knowledge, documented before in the therapeutic literature. It appears to be a new phenomenon which can only emerge at this point in modern history when these clients are older and have lived a life split between two worlds: Africa and England. They feel a deep sense of being dis-connected from Africa despite being born there. The sense of not belonging while in South Africa transforms almost magically to one of feeling a belonging when they are back on their ancestral lands. Together with fragmented identities, they are the inheritors of intergenerational transmission of both trauma and hope. To leave South Africa is to betray their family's hope for a better future after the World War II in Europe.

Exploring their experiences is necessarily exploring politics. Erikson (1982) noted that there is a vital societal 
aspect that contributes to psychological development. At each stage of development, he remarks, a social institution is organised to support this psychological development. Using this theory, in times of war and mass migration, however, the politics of the dominated and dominator become core to psychological development. In times of social upheaval, the social becomes disrupted and people are traumatised. In this case, the politics, embedded in the social, decides where people go to escape war and social chaos, and where to try again to re-invent themselves and re-start life. For Robert with no real roots, and Caitlin, a fish out of water, at odds with the world therapy is a painful process of realizing the predicament they find themselves in, of the throwness (Heidegger, 1962) of their existence. Moreover, within the context of the current South African politics of an unstable socio-political environment, their experiences of not belonging are possibly also partly reenforced in the light of the new dominant Black culture. As a result of this new cultural shift, it can become difficult to find a place and a sense of belonging when the (white cultural) space and place has changed in meaning from being once central, powerful, and dominant to less important/powerful, and thus, such clients are increasingly the outsiders within the Black (powerful) culture.

It is recognised that for some mature adults in their 50s and 60s such as Robert and Caitlin, as they enter the the second half of life (Jung, 1971) that this often a period in the life cycle that is a time for introspection, and psychological growth and development that occurs as a result, sometimes such introspection becomes quite painful. For Robert and Caitlin, as members of the third age (Weiss \& Bass, 2002) it could be construed that they are experiencing a later-life crisis (Robinson \& Stell, 2015) with negative flavourings (Lachman, 2004; O'Connor \& Wolfe, 1987 ) as opposed to a crisis with a positive turning point. As this crisis process commonly contains periods of heightened vulnerability and instability (King, 2001; Robinson \& Stell, 2015), together with a sense of being rootless and dislodged from their ancestral lands, Robert and Caitlin are experiencing a set of challenges unique to their socio-cultural heritage.

A further comment is that because these two clients' are older and thus face issues of ageing related to their developmental stage, they may also be identifying, to some extent, with their parents and their parents' origins. Freud (1917) noted that at this point in life there may be an identification with the parents. This would mean that for these clients such an identification would also shape and form their experiences, and that their longing for their ancestral land is perhaps partly also a longing for this connection to, and identification with, the parents and their origins.

Based on Robert's and Caitlin's experiences, the final concluding remark is to suggest that identity and belonging are linked to the place where one feels at home. This place of home can be called an emotional home. The emotional home provides a meaning to current life choices as well as to how the future is shaped. It gives meaning to the past because an emotional home cushions what was painful and makes the regrets of the past bearable because an emotional home provides psychic grounding, bearing and comfort in times of stress. With no emotional home, life is living without meaning. This links to the notion that land and home are not always the same thing. For Robert and Caitlin, South Africa is land but not home. They feel they have no belonging in South Africa because they have no (emotional) home. Their home is their ancestral land, and while they live on land that is not their ancestral land, they have no home and no sense of belonging. Therapy with this ageing group of adult clients is complicated as they must confront the existential concerns common at this age, and what this symbolises in terms of their finiteness and narrowing future horizons, in the context of intense feelings of being dis-located from their ancestral lands.

\section{References}

Aron, L. (1997). A meeting of minds: Mutuality in psychoanalysis. Hillsdale, NJ: The Analytic Press.

Benjamin, J. (2005). Creating and intersubjective reality. Commentary on a paper by Arnold Rothstein. Psychoanalytic Dialogues, 15, 447-457.

Becker, D. (2006). Therapy for the middle-aged: The relevance of existential issues. American Journal of Psychotherapy, 1 , 87-99.

Bergmann, M., \& Jucovy, M. (Eds.) (1982). Generations of the Holocaust. New York, NY: Basic Books.

Bradley, C.L., \& Marcia, J.E. (1998). Generativity-stagnation: A five-category model. Journal of Personality, 66, 39-64.

Brubaker, R., \& Cooper, F. (2000). Beyond "identity". Theory and Society, 29, 1-47.

Erikson, E.H. (1950). Childhood and society. New York, NY: W.W. Norton.

Erikson, E.H. (1968). Identity, youth and crisis. New York, NY: W.W. Norton \& Company.

Erikson, E.H. (1982). The life cycle completed. New York, NY: W.W. Norton \& Company.

Erikson, E.H., Erikson, J.M., \& Kivnick, H.Q. (1986). Vital involvement in old age: The experience of old age in our time. New York, NY: W.W. Norton \& Company.

Frank1, V. (1963). Man's search for meaning: An introduction to logotherapy. New York, NY: Pocket Books.

Freud, S. (1917). Mourning and melancholia. In J. Strachey (Ed.) The standard edition of the complete psychological works of Sigmund Freud, Volume 14. London, UK: Hogarth Press.

Freud, S. (1920). Beyond the pleasure principle. In J. Strachey (Ed.) The standard edition of the complete psychological works of Sigmund Freud, Volume 18. London, UK: Hogarth Press.

Garon, J. (2004). Skeletons in the closet. International Forum of Psychoanalysis, 13, 84-92.

Hunter, E.G., \& Rowles, G.D. (2005). Leaving a legacy: Toward a typology. Journal of Aging Studies, 19, 327-347.

Jackson, J.L. Jr. (2010). Theoretical counseling orientation: An initial aspect of professional orientation and identity. Unpublished doctoral thesis, University of Alabama, Tuscaloosa, AL, USA. 
James, J.B., \& Zarrett, N. (2006). Ego integrity in the lives of older women. Journal of Adult Development, 13, 61-75. doi:10.1007/s10804-006-9003-2

Jung, C.G. (1971). The portable Jung. New York, NY: Viking.

King, L.A. (2001). The hard road to the good life: The happy, mature person. Journal of Humanistic Psychology, 41, 51-72.

Kogan, I. (2002). "Enactment" in the lives and treatment of Holocaust survivors' offspring. Psychoanalytic Quarterly, 71, 251-272.

Kane, R.A. (1996). From generation to generation: Thoughts on legacy. Generations, 20(3), 5-9.

Kotre, J. (1984). Outliving the self: Generativity and the interpretation of lives. Baltimore, MA: Johns Hopkins University Press.

Kroger, J., \& Marcia, J.E. (2011). The identity statuses: Origins, meanings and interpretations. In S.J. Schwartz, K. Luyckx, \& V.L. Vignoles (Eds.), Handbook of identity theory and research (pp. 31-53). New York, NY: Springer. doi: 10.1007/978-1-4419-7988-9.

Lachman, M.E. (2004). Development in midlife. Annual Review of Psychology, 55, 305-331. doi:10.1146/annurev.psych.55. 090902.141521

Laslett, P. (1989). A fresh map of life: The emergence of the third age. London, UK: George Weidenfeld \& Nicolson Limited.

Levine, H.B. (1982). Toward a psychoanalytic understanding of children of survivors of the Holocaust. Psychoanalytic Quarterly, 51, 70-92.

Martinussen, M., \& Kroger, J. (2013). Meta-analytic studies of identity status and personality: Introduction and overview. Identity: An International Journal of Theory and Research, 13(3), 189-200. doi: 10.1080/15283488.2013.799474

Maslow, A.H. (1968). Towards a psychology of being. New York, NY: Van Nostrand.

Muhlegg, M. (2016). Projective identification in the intergenerational transmission of unsymbolized parental trauma: An adoptee's search for truth. Canadian Journal of Psychoanalysis, 1, 51-74.

Newton, J., Herr, J., Pollack, J., \& McAdams, D. (2014). Selfless or selfish? Generativity and narcissism as components of legacy. Journal of Adult Development, 21, 59-68. doi: 10.1007/s10804-013-9179-1

Neugarten, B.L. (1964). Personality in middle and late life. New York, NY: Atherton Press.

Neugarten, B. (1968). Middle age and aging. Chicago, IL: University of Chicago Press.

O’Connor, D.J., \& Wolfe, D.M. (1987). On managing midlife transitions in career and family. Human Relations, 40(12), 799-816. doi: 10.1177/001872678704001202

Robinson, O.C., \& Stell, A.J. (2015). Later-life crisis: Towards a holistic model. Journal of Adult Development, 22, 38-49. doi: 10.1007/s10804-014-9199

Ryff, C.D., \& Heincke, S.G. (1983). Subjective organization of personality in adulthood and aging. Journal of Personality and Social Psychology, 44, 807-816. doi:10.1037/00223514.44.4.807

Schwartz, S.J. (2002). In search of mechanisms of change in identity development: Integrating the constructivist and discovery perspectives on identity. Identity: An International Journal of Theory and Research, 2(4), 317-339.

Schwartz, S.J. (2011). The evolution of Eriksonian and neoEriksonian identity theory and research: A review and integration. Identity: An International Journal of Theory and Research, 1(1), 7-58.

Spinelli, E. (2015). Practising existential therapy: The relational world. ( $2^{\text {nd }}$ ed.). London, UK, Sage.

Stevens, R. (2008). Erik Erikson: Shaper of identity. Houndsmill, UK: Palgrave Macmillan.

Straker, G. (2004). Race for cover: Castrated whiteness, perverse consequences. Psychoanalytic Dialogues, 14, 405-422.

Suchet, M. (2004). A relational encounter with race. Psychoanalytic Dialogues, 14, 422-438.

Swartz, S. (2007). The power to name: South African intersubjective psychoanalytic psychotherapy and the negotiation of racialized histories. European Journal of Psychotherapy and Counselling, 9, 177-190.

Torges, C.M., Stewart, A.J., Nolen-Hoeksema, S. (2008). Regret resolution, ageing, and adapting to loss. The Psychology of Ageing, 23, 169-180.

Weiss, R.S., \& Bass, S.A. (2002). Introduction. In R.S. Weiss \& S.A. Bass (Eds.) Challenges of the Third Age: Meaning and purpose in later life (pp. 3-12). New York, NY: Oxford University Press.

Van Deurzen, E., \& Adams, M. (2011). Skills in existential counselling and psychotherapy. London, UK, Sage.

Van Deurzen, E., \& Arnold-Baker, C. (Eds.) (2005). Existential perspectives on human issues: A handbook for therapeutic practice. Basingstoke, UK: Palgrave Macmillian.

Viney, L.L., \& Tych, A.M. (1985). Content analysis scales to measure psychosocial maturity in the elderly. Journal of Personality Assessment, 49, 311-317.

Volkan, V. (1997). Bloodlines: From ethnic pride to ethnic terrorism. Boulder, CO:Westview.

Yalom, I. (1980). Existential psychotherapy. New York, NY: Basic Books.

Yalom, I. (2006). The Schopenhauser cure. London, UK: Harper Perennial.

Yalom, I., \& Leszcz, M. (2005). Theory and practice of group therapy. ( $5^{\text {th }}$ Ed.). New York, NY: Basic Books. 